\title{
New insights on CRISPR/Cas9-based therapy for breast Cancer
}

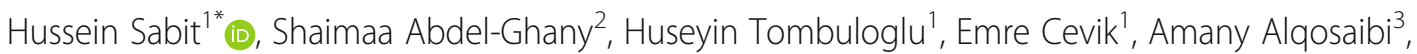 \\ Fatma Almulhim ${ }^{4}$ and Afnan Al-Muhanaa ${ }^{4}$
}

\begin{abstract}
CRISPR/Cas9 has revolutionized genome-editing techniques in various biological fields including human cancer research. Cancer is a multi-step process that encompasses the accumulation of mutations that result in the hallmark of the malignant state. The goal of cancer research is to identify these mutations and correlate them with the underlying tumorigenic process. Using CRISPR/Cas9 tool, specific mutations responsible for cancer initiation and/or progression could be corrected at least in animal models as a first step towards translational applications. In the present article, we review various novel strategies that employed CRISPR/Cas9 to treat breast cancer in both in vitro and in vivo systems.
\end{abstract}

Keywords: CRISPR/Cas9, Genome editing, Breast Cancer, Therapy

\section{Introduction}

During the past 20 years, several genome-editing technologies have been employed in a wide range of applications. Inspired with bacterial immune system, CRISPR/Cas9 came into existence as a revolutionizing powerful tool that facilitates correction, insertion, or deletion of genetic material both in vitro and in vivo systems. The discovery of this captivating bacterial immune defense mechanism resulted in an unprecedent revolutionary change in medical sciences [1] (Fig. 1). Upon transfecting cells, Cas9/gRNA complex can find its way to the target sequence (with the help of gRNA) to delete or insert a segment of DNA (with the aid of Cas9 enzyme) [2]. This triggers the cellular endogenous repair mechanisms, which might be one of two; first: non-homology end joining (NHEJ), which is an error-prone mechanism that generates indels and can be used to disrupt a specific gene.

\footnotetext{
* Correspondence: hhsabit@iau.edu.sa

'Department of Genetics, Institute for Medical Research and Consultations, Imam Abdulrahman Bin Faisal University, P. O. Box: 1982, Dammam 31441, Saudi Arabia

Full list of author information is available at the end of the article
}

Second: homology-directed repair (HDR) [3, 4]. When appropriately designed, a donor DNA could be inserted in the cleavage site to serve as a template on which the broken strand being built. The inserted strand might be normal or even contain a targeted mutation.

Breast cancer is a leading cause of death in females worldwide $[5,6]$. Breast cancer rate is rising worldwide with an expansion in forceful neoplasia in women. Around half of the breast malignancy cases and $60 \%$ of the deaths are happening in developing countries. There is an extensive distinction in breast cancer rate among Hispanic, Caucasian and Asian women, with Caucasian women being the most astounding and Asian women being the least $[7,8]$. Breast cancer research is a hot area in which CRISPR technology is in the core (Fig. 2).

CRISPR/Cas9 takes its place as an essential, efficient, and straightforward tool for cancer research, especially breast cancer [9]. This tool provides a means to insert, correct, and remove the faulty genes in a precise manner. Some limitations are facing applying this technology in all types of cancer; however, advancements are taking place [10].

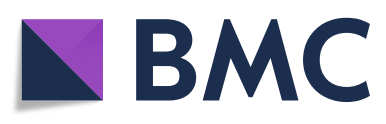

(c) The Author(s). 2021 Open Access This article is licensed under a Creative Commons Attribution 4.0 International License, which permits use, sharing, adaptation, distribution and reproduction in any medium or format, as long as you give appropriate credit to the original author(s) and the source, provide a link to the Creative Commons licence, and indicate if changes were made. The images or other third party material in this article are included in the article's Creative Commons licence, unless indicated otherwise in a credit line to the material. If material is not included in the article's Creative Commons licence and your intended use is not permitted by statutory regulation or exceeds the permitted use, you will need to obtain permission directly from the copyright holder. To view a copy of this licence, visit http://creativecommons.org/licenses/by/4.0/ The Creative Commons Public Domain Dedication waiver (http://creativecommons.org/publicdomain/zero/1.0/) applies to the data made available in this article, unless otherwise stated in a credit line to the data. 


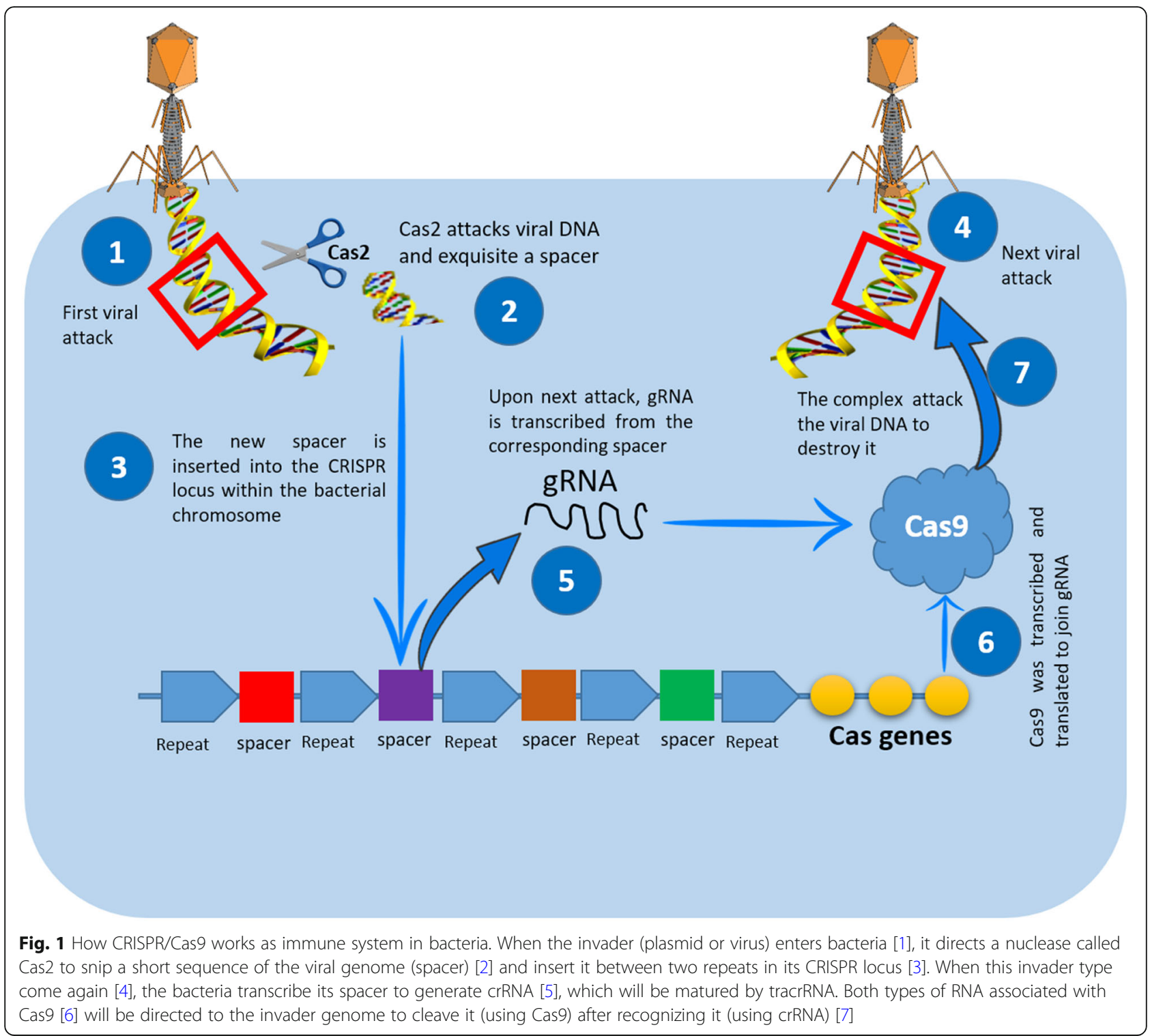

\section{CRISPR/Cas9: the Nature's gift}

CRISPR is primarily a gift from the Mother Nature, where scientists discovered it as prokaryotic immune system in bacteria and archaea. The work on CRISPR starts in the late 1980s with several landmarks in this long journey (Table 1), however, the foundational publications came in 2012 to demonstrate that a CRISPR system in Streptococcus pyogenes could be used for genome editing, opening a new gate for genome engineering. In these bacteria, Cas9 is responsible for cleaving the invaders' DNA. Guided by crRNA (CRISPR RNA) and tracrRNA (trans-activating crRNA which will be combined for editing purposes in vitro to produces gRNA), Cas9 can target a specific site in the genome and then produces double strand breaks (DSBs) [32, 33]. The complex composed of Cas9 and gRNA attacks the specific DNA sequence just upstream of the protospacer-adjacent motif (PAM) sequence, NGG (N represents any nucleotide) [34,35]. Almost 60 and 40\% of archaea and bacteria, respectively used CRISPR in the same manner, with minor differences [36]. CRISPR location, in this sense, serves as a memory deposition where the bacteria can store previous viral or plasmid attacks, and then used this information to defend itself against these invaders in the upcoming attacks.

\section{CRISPR/Cas9-based tumor modeling}

The classical method to transform a normal cell into malignant one requires multistep process that involve series of mutations to acquire such cells the hallmarks that characterize the malignant phenotype [37-39]. With exploiting the power of CRISPR/Cas9, many research groups were able to create such cancer models (Table 2). 


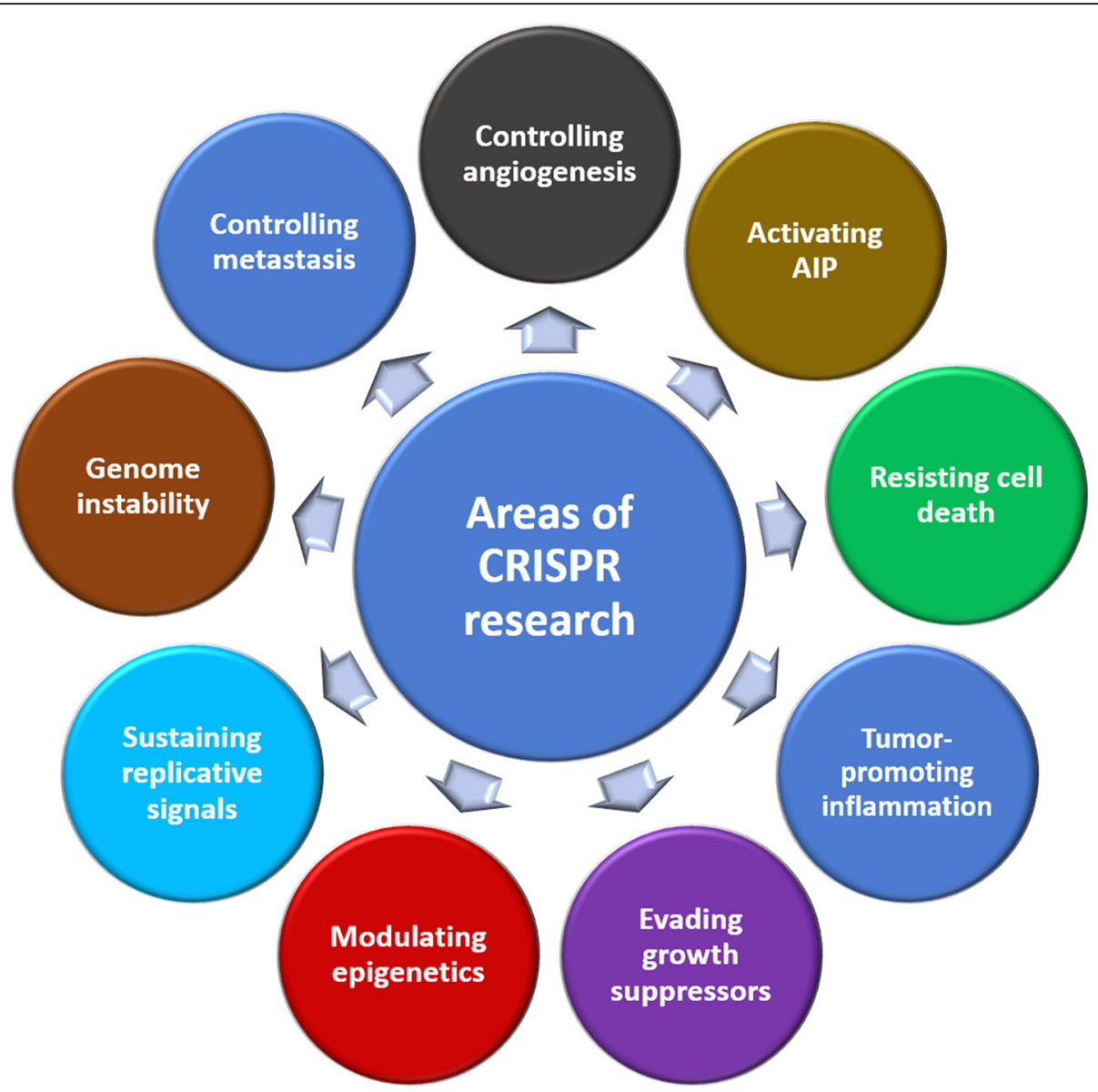

Fig. 2 Different research and treatment areas of CRISPR/Cas9 in breast cancer

Truncating APC tumor suppressor gene in gut cells was successful representative for a well-developed early event in colorectal cancer development. The Wnt signaling activators have been removed from the culture medium to select $A P C$-lacking human intestinal stem cells, leading to provoked $\beta$-catenin stabilization, and up-regulation of Wnt pathway [48] and [49]. Other approaches involve creating cells with activated $K R A S$ oncogene along with loss-of-function mutation. Furthermore, P53 was also inactivated using CRISPR/Cas9 [50, 51]. Using these approaches, a combination of mutations could also be generated, and then tested in by inoculating these edited cells into immunodeficient mice. This cancer model answers an immense question, whether the cancer-causing mutation occur randomly or in a precise time order.

Similar strategies have been used to transduce a nonmetastatic mouse lung cancer cell line with CRISPR/ Cas9 which targets several protein-coding genes along with miRNA precursors. Chen, Peng [52] recorded a massive growth of tumor and lung metastasis upon inoculating the modified cells into immunodeficient mice. By deep sequencing, the team discovered several novel genes whose activation was crucial to tumor growth and metastasis. This approach allows for recapitulating the process of tumor evolution and metastasis, which in turn, might help in designing specific therapies targeting the faulty gene(s) [53].

\section{CRISPR/Cas9-based transcriptome reprogramming}

Transcriptional programs control almost all aspects of organism's life from early developmental stages until death [54]. Cancer, as an abnormal state of the cells has its own specific transcription program, which has been validated by CRISPR in several cancer types including ovarian, and breast carcinomas, where cancer cells were found to display a cell-specific transcription regulation pattern, with epigenetic modulations being the main affecting factors $[55,56]$. This program could be disrupted by inhibiting $C D K 7$, which represents a potential therapeutic option for breast cancer, especially estrogen receptor (ER) mutation-mediated endocrine-resistant type. The most impressive feature is that $C D K 7$ inhibition not only prejudices the cell growth of breast cancer, but also 
Table 1 The timeline of genome editing groundbreaking achievements

\begin{tabular}{|c|c|c|}
\hline Year & Contributor & Contribution \\
\hline 1987 & Yoshizumi Ishino et al. & $\begin{array}{l}\text { Discovered some repeats in the IAP gene in Escherichia coli. They could not identify the main function of } \\
\text { these repeats [11]. }\end{array}$ \\
\hline 1993 & Francisco Mojica et al. & $\begin{array}{l}\text { Characterized what is now called a CRISPR locus as a molecular genetics' memory of MGE (mobile genetic } \\
\text { element) that previously attacked the bacteria cell. They also discovered tandem repeats (TREPs) in } \\
\text { Haloarchaea [12]. }\end{array}$ \\
\hline 1996 & Yang-Gyun Kim et al. & $\begin{array}{l}\text { Genetically engineered the first restriction-modification enzymes with the ability to cut at specific target se- } \\
\text { quences. This enzyme was amenable to be used in editing genomes [13]. }\end{array}$ \\
\hline 2000 & Jeff Smith et al. & $\begin{array}{l}\text { Conducted several experiments to show that Zinc Finger Nucleases (ZFN) can generate double-stranded } \\
\text { DNA breaks, and hence could be used as a genome-editing tool [14]. }\end{array}$ \\
\hline 2002 & Marina Bibikova et al. & Used Zinc fingers for the first time to disrupt genes in the fruit fly Drosophila melanogaster [15]. \\
\hline 2002 & Ruud Jansen et al. & Coined the term CRISPR that stands for Clustered Regularly Interspaced Short Palindromic Repeats [16]. \\
\hline 2004 & Alan Lloyd et al. & $\begin{array}{l}\text { Announced the first plant genome modified with the Zinc Finger Nuclease, that is the tool that could be } \\
\text { used in editing genomes. This tool could also be used to create models of human genetic diseases [17]. }\end{array}$ \\
\hline 2005 & Alexander Bolotin et al. & $\begin{array}{l}\text { Discovered a new CRISPR locus in streptococcus thermophilus. He also noted that the spacers, which have } \\
\text { homology to viral genes, share a common sequence at one end. This sequence would be later known as } \\
\text { protospacer adjacent motif (PAM) [18]. }\end{array}$ \\
\hline 2006 & Eugene Koonin et al. & $\begin{array}{l}\text { Suggested that CRISPR is an immune system that works by interference with RNA in bacteria. He also } \\
\text { classified about } 25 \text { distinct Cas families, and predicted their new functions [19]. }\end{array}$ \\
\hline 2008 & John van der Oost et al. & $\begin{array}{l}\text { Showed that spacer sequences are transcribed into CRISPR RNAs (crRNAs), that guide Cas nuclease to the } \\
\text { target DNA of the invader [20]. }\end{array}$ \\
\hline 2010 & Sylvain Moineau et al. & $\begin{array}{l}\text { Indicated that CRISPR/Cas9 generates DSBs } 3 \text { nucleotides upstream of the PAM sequence in target DNA } \\
\text { [21]. }\end{array}$ \\
\hline 2011 & Emmanuelle Charpentier et al. & $\begin{array}{l}\text { Discovered another type of RNA found in the CRISPR system's components called trans-activating RNA } \\
\text { (tracrRNA). She indicated that tracrRNA works simultaneously with crRNA in directing the Cas9 protein to } \\
\text { cut the target sequence [22]. }\end{array}$ \\
\hline 2012 & Virginijus Siksnys et al. & $\begin{array}{l}\text { Indicated that Cas9 consists of two domains, which are RuvC and HNH, and that the first domain cuts in } \\
\text { the distant DNA strand, while the second cuts in the strand where the integration between crRNA and } \\
\text { DNA occurs [23]. }\end{array}$ \\
\hline 2012 & $\begin{array}{l}\text { Jennifer Doudna and } \\
\text { Emmanuelle Charpentier }\end{array}$ & Engineered the dual-tracrRNA:crRNA as a single RNA chimera called gRNA [24]. \\
\hline 2013 & Feng Zhang et al. & $\begin{array}{l}\text { Announced the use of CRISPR/Cas9 in the editing of human genes, the matter that opened the door to } \\
\text { the use of CRISPR in the medical field [25]. }\end{array}$ \\
\hline 2015 & Feng Zhang et al. & Introduced Cpf1 as a new nuclease that works in more efficient way than Cas9 [26]. \\
\hline 2015 & Junjiu Huang et al. & Reported the first application of CRISPR to non-viable human embryos [27]. \\
\hline 2016 & Kamel Khalili et al. & $\begin{array}{l}\text { Used CRISPR/Cas9 to edit HIV out of a human immune cell DNA, and therefore, prevent the reinfection of } \\
\text { unedited cells too [28]. }\end{array}$ \\
\hline 2016 & Kevin Esvelt et al. & Developed the CRISPR/Cas9 gene drive [29]. \\
\hline 2017 & Jennifer Doudna et al. & $\begin{array}{l}\text { Developed a CRISPR-Gold, which is a new version of the CRISPR/Cas9 gene editing, in this new technology, } \\
\text { they used gold nanoparticles for delivering the CRISPR/Cas9 gene-editing system into cells [30]. }\end{array}$ \\
\hline 2018 & Norbert Reich et al. & $\begin{array}{l}\text { Introduced light-triggered genome editing approach using hollow gold nanospheres. This approach is } 100 \\
\text { to } 1000 \text { times more efficient than current genome editing methods [31]. }\end{array}$ \\
\hline
\end{tabular}

the resistance of the estrogen-responsive MCF7 breast cancer cells [57].

Prior CRISPR, ZFNs (zinc finger nucleases) and TALE Ns (transcription activator-like effector nucleases) were used to activate and suppress genes as a strategy for cancer therapy. A brief comparison between the three major genome editing tools is highlighted in (Table 3). The structure of both tools made them suitable for holding activators and suppressors [58, 59]. For the time being, these activators and suppressors are easily fused to dCas9, a mutation of Cas9 without endonuclease activity. Recently, more dCas9-based transcription activator/suppressors were made available [60]. Aptamers been used for re-programming the epigenome aiming to reactivate the hypermethylated tumor suppressor genes (TSGs) to recover the growth suppressor activity exerted by these TSGs $[61,62]$. This strategy works in liver, colon, breast, and lung cancers. This approach is an alternative to epigenetic-modified small molecules/drugs, which might have undesirable side effects. Furthermore, dCas9 was efficiently used for targeted demethylation of $B R C A 1$ promoter using the demethylation domain of 
Table 2 CRISPR/Cas9- based cancer mouse models (reviewed in [40])

\begin{tabular}{|c|c|c|c|c|}
\hline Cancer type & Mouse strain & Vector & Target gene(s) & Reference \\
\hline Lung adenocarcinoma & $\mathrm{Kras}^{|s|-G 12 \mathrm{D} /+}$ & Lentivirus & NKX, PTEN, APC & [41] \\
\hline Lung adenocarcinoma & CD1 & Adenovirus & EML4 & {$[42]$} \\
\hline Burkitt lymphoma & Arf/- E $\mu \mathrm{Myc}$ & Retrovirus & p53 & [43] \\
\hline Glioblastoma & Crl:CD1 mice & Transfection & TRP53, PTEN, NF1 & [10] \\
\hline Acute myeloid leukemia & C57BI/6 mice & Lentivirus & DNMT3A, EZH2, RUNX1 & [1] \\
\hline Burkitt lymphoma & E $\mu-$-Myc mice & Lentivirus & p53 & [44] \\
\hline Pancreatic adenocarcinoma & KrasLSL-G12D/+ & Lentivirus & $\angle K B 1$ & {$[45]$} \\
\hline Lung metastases & $\mathrm{Kras}^{\mathrm{G} 12 \mathrm{D} /+; p 53^{-/-}}$ & Lentiviral & Multiple hits & {$[46]$} \\
\hline Tumor regression & Foxn $1^{\text {nu }}$ mice & Transfection & PKC $\beta$ A509T & [47] \\
\hline
\end{tabular}

TET1-the enzyme that converts 5-mC (5-methylcytosine) into 5-hmC (5-hydroxymethylcytosine)- in cervical and breast cancer cells. CRISPR/Cas9-based epigenome editing was used also to repress interleukin receptors (IL1R1) and tumor necrosis factor $\alpha$ receptor (TNFR1) in human adipose-derived stem cells. This may open the gate to control various kinds of inflammations that accelerate the growth of different types of cancers [63-65].

Yet, an array of epigenetics modifiers based on dCas9 is introduced to modify the epigenetics marks as a new way to treat several diseases including cancer.

\section{Editing DNA for cancer therapy}

Although CRISPR technology was used in cancer modeling and screening, it also offers a straightforward way to target-specific cancer therapy. Many trials have been conducted using CRISPR to combat this life-threatening disease. E6 and E7 in the HPV have been challenged with CRISPR/Cas9 to induce the apoptotic machinery and inhibit growth in cervix cancer cell line in vitro [66]. Meanwhile, CRISPR/Cas9-mediated deletion of miRNAbinding site located in the UTR (un-translated region) of F1H1-the gene that regulate angiogenesis in NSCLC cells - resulted in recovering the vascular abnormalities that characterize lung cancer [67].

The oncogene HER2 exons are also a target for CRIS PR intervention, where a mutation in the exon12 of HER2 resulted in a dominant negative mutant phenotype [68]. The mutant HER2 was found to inhibit the MAPK/ $E R K$ axis of HER2 signaling pathway required for the proliferation of breast cancer cells. Controlling breast cancer via CRISPR-mediated editing of HER2 is enhanced in the presence of PARP inhibitors that is

Table 3 Comparison between the three main genome-editing tools

\begin{tabular}{|c|c|c|c|}
\hline & ZFN & TALEN & CRISPR \\
\hline Nature & $\begin{array}{l}\text { Engineered protein to target specific DNA } \\
\text { sequences }\end{array}$ & $\begin{array}{l}\text { Engineered protein to target specific DNA } \\
\text { sequences }\end{array}$ & $\begin{array}{l}\text { Short sequence of RNA that can target } \\
\text { specific DNA sequences }\end{array}$ \\
\hline $\begin{array}{l}\text { Target/ } \\
\text { sensitivity }\end{array}$ & Protein-DNA interaction, less sensitive & Protein-DNA interaction, less sensitive & RNA-DNA interactions, highly sensitive \\
\hline $\begin{array}{l}\text { Size of } \\
\text { recognized } \\
\text { target }\end{array}$ & $18-36 \mathrm{nt}$ & $30-40 \mathrm{nt}$ & $22 \mathrm{nt}$ \\
\hline $\begin{array}{l}\text { Off } \\
\text { targeting }\end{array}$ & High & Moderate & Low \\
\hline Efficiency & Moderate & Moderate & High \\
\hline $\begin{array}{l}\text { Nuclease - } \\
\text { D/M }\end{array}$ & Fokl - dimer & Fokl - dimer & Cas9 - monomer \\
\hline $\begin{array}{l}\text { Mode of } \\
\text { action }\end{array}$ & $\begin{array}{l}\text { For ZFN to work, it requires two sets to } \\
\text { hybridize each to each DNA strand around } \\
\text { the target sequence }\end{array}$ & $\begin{array}{l}\text { For TALEN to work, it requires two sets to } \\
\text { hybridize each to each DNA strand around } \\
\text { the target sequence }\end{array}$ & $\begin{array}{l}\text { In the presence of gRNA, Cas9 can reach } \\
\text { the target DNA sequence and generate } \\
\text { double strand breaks. }\end{array}$ \\
\hline Cytotoxicity & Moderate & Low & Low \\
\hline $\begin{array}{l}\text { Multiple } \\
\text { targets }\end{array}$ & Difficult & Difficult & Doable \\
\hline $\begin{array}{l}\text { Cost/ } \\
\text { benefits }\end{array}$ & High cost and time consuming & High cost and time consuming & Low cost and less time needed \\
\hline
\end{tabular}


involved in DNA repair and cell death [69]. This combinational approach represents a potential therapeutic option for breast cancer.

Genome-wide synthetic lethal CRISPR screens were performed to determine novel as a therapeutic option for treating endocrine resistant breast cancer. CRISPR screens identified a gene which is associated with the response to endocrine therapy in plentiful of clinical studies [70].

To this end, they tried to combine two therapeutic components; ordinary endocrine therapy and an inhibitor for the gene identified by the CRISPR screens to subdue the endocrine resistance either in cell line or patient-derived xenograft models.

\section{Protein degradation in breast cancer}

One of the important ways to enhance tumor cell proliferation is the increased activity of protein degradation. Of these protein-degrading enzymes, comes the $26 \mathrm{~S}$ proteasome, a multi-catalytic enzyme that is responsible for protein degradation including cell cycle regulation and apoptosis-related proteins [71, 72]. In cancer models, it has been indicated that proteasome inhibitors have anticancer and apoptosis-enhancing properties. Furthermore, it sensitizes tumor cells to the extrinsic and intrinsic pro-apoptotic signals. Therefore, proteasome has become a target for antitumor treatments. It has been indicated that breast cancer proliferation is controlled by a site-specific proteasome phosphorylation process [24], and the interfering and disruption of this process might be of value in controlling the disease.

Using CRISPR/Cas9, dual-specificity tyrosine-regulated kinase 2 (DYRK2) knockout (the enzymes that phosphorylate the proteasome components) was established to disrupt tumorigenesis of the proteasome-addicted human breast carcinoma cells in mice [73].

ER-positive breast cancer could be treated via inhibition of estrogen synthesis using aromatase inhibitors (AI) or via tamoxifen and fulvestrant that compete estrogen on ER $\alpha$. Mutations in ER $\alpha$ such as ER $\alpha$ Y $537 \mathrm{~S}$ and ER $\alpha$ D538G results in rendering advanced metastatic breast cancer insensitive to AI and tamoxifen [74]. To validate the effect of these mutations, breast cancer positive ER $\alpha$ model was created using CRISPR/Cas9 in which the wild type version of $\mathrm{ER} \alpha$ was replaced with $\mathrm{ER} \alpha \mathrm{Y} 537 \mathrm{~S}$ or ER $\alpha \mathrm{D} 538 \mathrm{G}$. These mutant cells are partially resistant to antiestrogen, i.e., it is manifesting estrogen independent. Antiestrogen resistance of the mutant cells was found to be associated with upregulation of the protein response that reduces the ER $\alpha$ degradation [75].

Migration and invasion enhancer (MIEN1) are involved in cancer progression and metastasis of breast cancer. It has been found that increased expression of
MIEN1 might enhances tumor migration and metastasis. Using CRISPR/Cas9, a targeted deletion in this gene effectively led to repeal its expression and hence to control the disease spearing. This approach allows us to deeply understand the role MIEN1 plays in carcinogenesis and tumor progression, which might be transformed in the future as a breast cancer therapeutic option [76].

Mutations in PTEN (phosphatase and tensin homolog) gene, are fundamental step in the carcinogenesis process. PTEN is a tumor suppressor gene, involved in the cell cycle regulation and controlling the proliferation rate. Using CRISPR/Cas9, invasive lobular breast carcinoma (ILC)-initiating cells was targeted to disrupt PTEN in mice mammary gland-specific loss of E-cadherin. This approach can be used for rapid in vivo testing of putative tumor suppressor genes underlie ILC [77].

\section{CRISPR-mediated immunotherapy}

Molecular subtypes of breast cancer have different characteristics based on which cancerous cells respond to the intrinsic (immune system) or extrinsic (environment) stimuli (Fig. 3). One unique approach to fight breast cancer cells is using a CRISPR/Cas9-edited macrophages in which signal-regulatory protein alpha (SIRP- $\alpha$ ) is eliminated. The edited macrophages will be unable to receive the "do not eat me" signal of CD47-SIRP $\alpha$ from the cancer cells leading to destroy it. On the other hand, $\mathrm{T}$ cells could be engineered to express a cancer-specific T-cell receptor (TCR). Taking into consideration that the endogenous TCRs might compete with engineered one, endogenous TCR- $\beta$ was knocked out in the recipient cells via CRISPR/Cas9. The resultant CRISPR-edited $\mathrm{T}$ cells were a 1000-fold more sensitive to cancer antigen than normal TCR-transduced T cells [78]. Meanwhile, CAR $\mathrm{T}$ cells were edited by CRISPR/Cas9 to generate inhibition-resistant universal CAR T cells [79].

\section{Editing cancer epigenome}

CRISPR/Cas9-mediated epigenome editing is one of the potential tools to treat several cancers including breast cancer. The gene approach involves the fusion of Cas9 with a transcription repressor/activator for repression and activation, respectively. The Krüppel-associated box (KRAB) is an example, where the fused dCas9-KRAB was capable to induce locus-specific deposition of H3K9me3 at the HS2 enhancer region, resulting in silencing of multiple globin genes in K562 cells [80]. Cancer cells normally contain a wide variety of genetic mutations either in TSGs or in oncogenes [37, 81]. Using CRISPR/Cas9, specific loss-of-function or gain-offunction mutations could be achieved. This approach enables scientists to identity the causative gene in different types of cancers including breast cancer. Targeting these genes might help in controlling the corresponding 


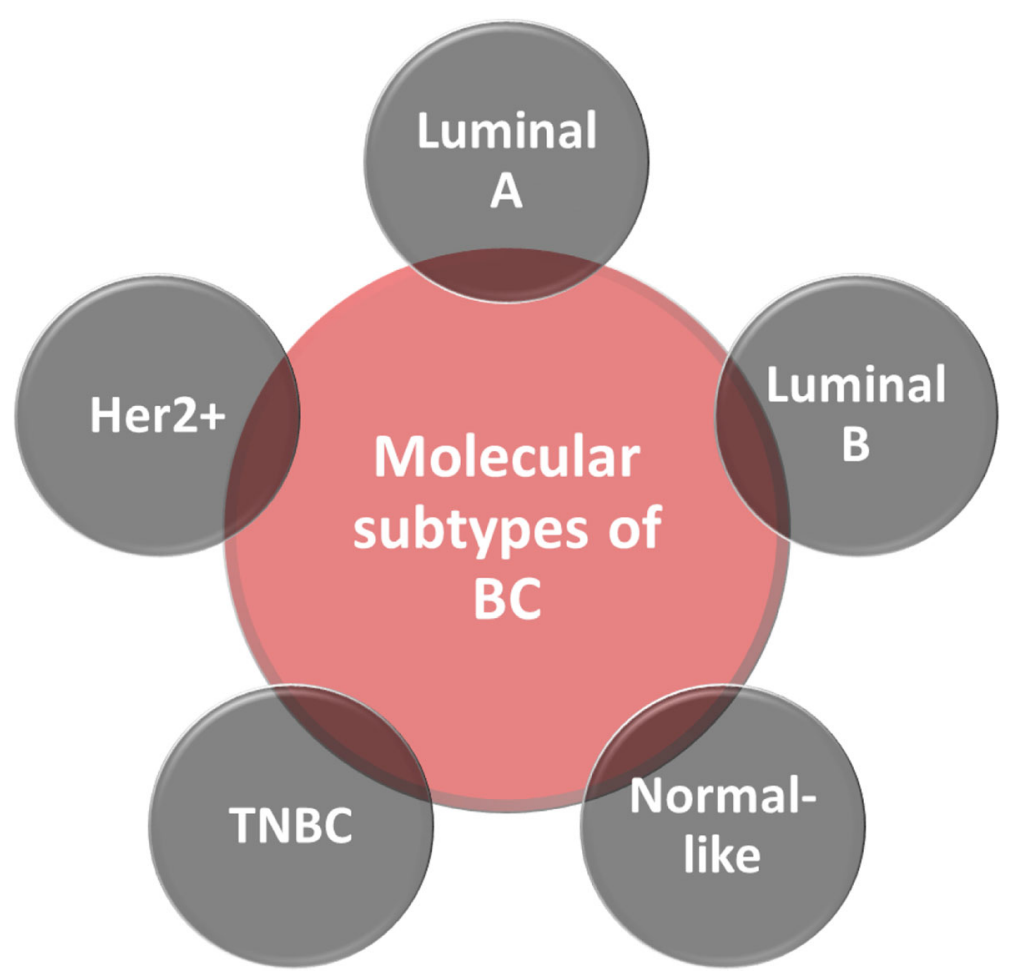

Fig. 3 The molecular subtypes of breast cancer

cancer. Meanwhile, The ER regulator $S R C-1$ gene plays a central role in the ability of ER tumors to adapt and facilitate metastatic disease progression. $S R C-1$ coactivates ER to regulate a network of proliferation- and differentiation-associated genes critical to breast cancer progression. Using CRISPR/Cas9-based epigenetic, silencing of $S R C-1$ resulted in a poor expression of the proliferation- and differentiation-associated genes, which might control the progression of breast cancer and/or tumor metastasis [82].

\section{CRISPR barcoding}

Molecular barcoding using mutations induced by Cas 9 is an influential method for recording biological information on real time, however, its applications in mammalian systems is relatively limited [83]. Breast cancer progression and proper response to treatments are major aspects being affected with the large count of mutations accumulated in malignant cells $[84,85]$. Although its significant clinical impact, few studies have addressed the intratumor heterogeneity to deeply understand the causative genes and along with underlying molecular mechanisms. Several research groups used CRISPR/Cas9 to introduce oncogenic mutation in a subset of cells within a mass population [86]. These targeted mutations were linked with silent mutations that serve as a genetic barcode and can be identified by qPCR. This approach has been used in different malignant cells to introduce nonsense or missense mutations in TP53, resulting in an inactive or a dominant-negative form of this TSG. In this context, current genome editing approaches lack the capability to generate specific alterations with tumor growth-controlling properties making it hard to repair oncogenic mutations. Initial tracing of the edited cells using CRISPR-barcoding overcomes this limitation [87-89].

\section{CRISPR/Cas9 limitations and challenges Drug resistance}

One of the most important challenges in breast cancer therapy is the drug resistance [90]. Accordingly, identifying the drug resistance-related genes might set a new stage of treating breast cancer potentially by using CRIS PR/Cas9 technique. The main limitation faces CRISPR application in editing these genes is the off-target activity of Cas9. Various approaches were used to tackle this problem, although the defined mechanisms of high specificity of gRNA remains unclear [91, 92].

Different methods have been introduced to screen for the edited alleles created by CRISPR/Cas9. Among these methods the "pop-in/pop-out" established by Kühn and Chu, in which the isolation of edited alleles became easier [93].

One of the biggest limitations of applying CRISPR/Cas9 for clinical treatments is the presence of a type of antigenspecific T-cells works against Cas9. This, of course, limits the 
activity of the nuclease and, subsequently, the effectiveness of the entire editing process. Furthermore, the immune system can recognize and eliminate the edited cells. Several reviews highlighted the potential immunological concerns of using CRISPR/Cas9 in clinical settings [3, 94-96]. However, more studies are needed to elucidate the function of Cas9specific T-cells during treatment. These studies should also address engineering a type of Cas9 that can escape the host immune system or at least fusing an immune-compromising agent within the Cas9-harboring cassette.

Another challenge is the delivery system that suit the hard-to-transfect cells/tissues. Several non-viral delivery methods are there including using nanoparticles, electroporation, and direct injection. These methods have its own drawbacks where it needs in general large quantities of the prepared plasmids along with tools required.

Viral and bacteriophage-derived vectors represent the easiest way to deliver CRISPR/Cas9 inside the target cells, however, more preclinical studies are mandatory to characterize its level of geno- and cellular toxicity [97]. In addition, the pharmacokinetics and pharmacodynamic properties of the complex must be identified. Some trials have been conducted to effectively deliver CRISPR system into cells including the encapsulation of the system into lipopolymer with cell specific aptamer for cancerspecific targeting. This method appears to be more efficient in CRISPR system delivery compared to the traditional viral and non-viral delivery methods [98]. Furthermore, Wang, Song [4] used CRISPR/Cas9 delivery system comprising PEGylated nanoparticles based on the $\alpha$-helical polypeptide PPABLG. Supported by the high membrane-penetrating capability of the polypeptide, P-HNPs attained competent cellular internalization and endosomal escape, which is considered an efficient way to system delivery.

\section{Off-targeting}

The major challenge facing CRISPR/Cas9-based therapeutics is the off-target possibility, where Cas9 can cleave DNA at unintended sites [99]. To minimize the off-target effects, the design of gRNA should be of high precision, especially the 5' end sequence composition. Therefore, several algorithms have been introduced in the recent decade to maximize the on-target and minimize the off-target (Table 4). On the other hand, the activity of Cas9 is considered a crucial defining factor that identify the off-target effect [100]. The higher the activity of Cas9, the increased the level of off-targets (due to non-specific cleavage). Thus, adjusting the Cas9 activity might help in reducing the off-target effects. To this end, various studies were conducted to optimize Cas9 activity. One of the ways to produce conditionally expressed Cas9 is to clone the Cas9-encoding gene under the control of tetracycline-responsive element promoter. This might help in controlling the expression of Cas9 in the presence of tetracycline/doxycycline. Furthermore, cloning gRNA under the same promoter was found to be a good alternative to control off-target cleavages [101-103].

Another effective approach to control the level of Cas9 expression to decrease off-targets is constructing a version of Cas9, which is 4-hydroxytamoxifen-dependent via attaching a hormone-binding domain of the estrogen receptor to Cas9. In this case, Cas9 is released to the cytoplasm in the presence of 4-hydroxytamoxifen leading to control Cas9 activity [104]. Other approaches implicated the self-splicing properties of protein segments "intein" that can excise itself and join the remaining portions with a peptide bond to render Cas9 nuclease active only in the presence of 4-hydroxytamoxifen [34]. Interestingly, these two systems of controlling the expression of Cas 9 might be used soon as a tool to design vectors for therapeutic interventions.

Table 4 A group of web-based algorithm for gRNA designing

\begin{tabular}{|c|c|c|}
\hline Tool name & $\begin{array}{l}\text { Off-target } \\
\text { analysis }\end{array}$ & Webpage link \\
\hline CRISPR Design Tool & Yes & https://www.synthego.com/products/bioinformatics/crispr-design-tool/ \\
\hline Cas-Designer & No & http://www.rgenome.net/cas-designer/ \\
\hline CRISPR MultiTargeter & No & http://www.multicrispr.net/ \\
\hline $\begin{array}{l}\text { CRISPR Genome Analysis } \\
\text { Tool }\end{array}$ & & http://cbc.gdcb.iastate.edu/cgat/ \\
\hline GeneArt & Yes & $\begin{array}{l}\text { https://www.thermofisher.com/sa/en/home/life-science/genome-editing/geneart-crispr/geneart-crispr- } \\
\text { search-and-design-tool.html/ }\end{array}$ \\
\hline ZiFiT Targeter Version 4.2 & No & http://zifit.partners.org/ZiFiT/ChoiceMenu.aspx/ \\
\hline $\begin{array}{l}\text { CRISPR/Cas9 target online } \\
\text { predictor }\end{array}$ & Yes & https://crispr.cos.uni-heidelberg.de/ \\
\hline Cas9 online designer & Yes & http://www.rgenome.net/cas-designer/ \\
\hline $\mathrm{CHOPCHOP}$ & Yes & http://chopchop.cbu.uib.no/ \\
\hline sgRNAcas9 & Yes & http://www.biootools.com/col.jsp?id=103/ \\
\hline E-CRISP & Yes & http://www.e-crisp.org/E-CRISP/ \\
\hline
\end{tabular}


Furthermore, target site recognition by Cas 9 requires the recognition of a specific short motif (PAM, protospacer recognition motifs). To tackle this problem, an engineered Cas9 derivatives with altered PAM specificities was designed [105]. Meanwhile, a split variant of Cas9 was fused with low expression protein domain. In this composition, Cas9 became active when stimulated with blue light, allowing researchers to control the activity of Cas9 in vitro and in vivo [106].

On-targeting is determined generally by several factors including gRNA physical design, the nuclease structure (Cas9), the ratio of gRNA/Cas9 in the media, and finally the target site uniqueness [107]. Various approaches were introduced to tackle off-targeting problem including down-sizing the gRNAs to 20 bases, which could increase its specificity by 5000 -fold [105]. Other approach involves mutating the Cas9 active domain to alter its cleavage function aiming to enforce it to use two-enzyme unite to make double stand break (DSB) [108]. Furthermore, fusing dCas 9 with FokI to increase the specificity was suggested [109]. Altering the electric polarity of the Cas9 two domain; $\mathrm{HNH}$ and RuvC to reduce off-target editing, was proved to be more specific with reduced off-target score [103]. One research group has tried to introduce the Cas9 in its protein form rather than being inserted as a Cas9coding DNA in the plasmid might enhance the on-target capacity and reduce off-target mutations [110].

For CRISPR/Cas9 technology to be applied in clinical settings, the challenge of controlling Cas9 activity should be tackled, taking into consideration that the easy and straightforward the approach, the higher the chance to be used as a therapeutic option for many types of cancer, including breast cancer.

\section{Animal studies}

Kleinstiver et al. [77] described a novel approach to validate candidate TSGs that have a role on invasive lobular breast carcinoma by intraductal injection of lentiviral vector that encodes CRISPR/Cas9 system, Cre recombinase, or a combination of the two components in female mice with conditional alleles E-cadherin gene. Thier work enables to identify the putative TSG implicated in invasive lobular breast carcinoma in mice.

In the same context, breast cancer-related miRNAs such as miR-23b and miR-27b were knocked out using CRISPR/Cas9 to examine the breast cancer model in vitro and in vivo. In vitro knock out of miR-23b and miR-27b revealed that these miRNAs are oncogenic miRNAs in MCF7 breast cancer cells in mice. Results also indicated that miR-27b could have tumor suppressive activity under certain circumstances [111].

A knock-in mice with Cre-conditional expression of a cytidine base editor was generated to test the utility for precise somatic engineering of missense mutations in breast cancer. A designed sgRNA-encoding vector was delivered to induce point mutation to assess the effect of defined allelic variants on mammary tumorigenesis. This model was successfully applied in a model of TNBC [112]. Other base editing trial in breast cancer was conducted by [113].

\section{Ethical issues}

CRISPR/Cas gene editing technologies have emerged as powerful tools in the study of oncogenic transformation [114]. Although its benefits, it can raise persistent ethical concerns [115]. Recently, CRISPR/Cas9 has been picked as favored technique for genome editing because of its high level of straightforwardness along with the requirements of minimal efforts. These properties make this strategy alluring to be utilized by any molecular science lab, yet the issue is that it can be utilized for any reason except if it is managed [116].

One of the main drawbacks of this technology is the Off-target effects that might have several pathogenic consequences [115]. On the other hand, on-targets may also result in a wide range of deletions and genomic rearrangements [117].

\section{Future perspectives}

CRISPR/Cas9 is not only a powerful tool to edit genomes in laboratories, but also it can serve as a therapeutic option after ensuring its safety profiles. Prior applying CRISPR/Cas9 directly to human cells, animal cancer models serve as a preclinical platform in which this tool could be used to create models to deeply elucidate the causative genes of such disease. Furthermore, these models could be investigated in parallel to the cancer patients, which make it easy to rapidly identify different resistance mechanisms and to establish new strategies for treating the disease. Furthermore, since Doudna and Charpentier announced that CRISPR technology could be used in lab as an RNA-guided genome editing tool, CRISPR technology became the ideal platform to personalized medicine, where it offers unique opportunity to edit human genome easily and straightforwardly in specific manner. For the time being, CRISPR capable to correct single mutation in human, and with pushing the technology to its upper limits, multiple genes could be corrected, removed, replaced, or inserted in vivo at the same time in one single hit. Applications of CRISPR cover almost all the biological and biomedicine research [41].

\section{Conclusion}

CRISPR/Cas9 is a groundbreaking technology that can be used to cure several human diseases including cancer. In this review, we highlight the most advanced CRISPR/ Cas9-based approaches to tackle the challenges associated with many types of cancer including breast cancer. Breast cancer is not only caused by genetic mutations 
but also by epigenetic one, making CRISPR an ideal tool to deal with mutations underlie this disease. Although CRISPR has a profound range of application especially in human diseases, some ethical issues have arisen fearing from the misuse of this technology. The consequentialist arguments mainly seek the balance between potential benefits and risks in ethical considerations. Nonetheless, the use of CRISPR/Cas9 in somatic cells is ethically accepted because of its low risk compared to its benefits. In addition, germline applications for human embryos have high risks compared to its potential benefits, where it may have unknown harmful effects on future offspring. Nevertheless, one can argue that, for example, correcting the faulty version of the $M Y B P C 3$ gene that causes hypertrophic cardiomyopathy in fetus might help in the selection of the healthy embryos for implantation as a potential therapeutic intervention to treat monogenic inherited disorders.

\begin{abstract}
Abbreviations
CRISPR: Clustered Regularly Interspaced Short Palindromic Repeats; Cas9: CRISPR associated protein 9; NHEJ: Non-homology end joining; HDR: Homology-directed repair; tracrRNA: Trans-activating crRNA; crRNA: CRIS PR RNA; gRNA: Guide RNA; PAM: Protospacer-adjacent motif;

APC: Adenomatous polyposis coli; dCas9 : Inactivated or 'dead' Cas9; indels : Small insertions and deletions; KRAS : Kirsten rat sarcoma viral oncogene homolog; $\beta$-catenin: Beta-catenin; Wnt: Wingless/Integrated; miRNA: MicroRNA; CDK7: Cyclin-dependent kinase 7; MCF7: Michigan Cancer Foundation -7; ZFNs: Zinc finger nucleases; TALENs: transcription activatorlike effector nucleases; BRCA1: Breast cancer susceptibility gene; TET1: TenEleven Translocation-1; 5-mC: 5-methylcytosine; 5-hmC: 5hydroxymethylcytosine; IL1R1: Interleukin receptors; TNFR1: Tumor necrosis factor a receptor; HPV: Human papillomavirus; UTR : Un-translated region; NSCLC: Non-small cell lung cancer; HER2: Human epidermal growth factor receptor 2; MAPK: Mitogen-activated protein kinase (MAPK); ERK: Extracellular signal-regulated kinase; F1H1: Distal 59-flanking region F1, haplotype 1; PARP: Poly(ADP-ribose) polymerase; DYRK2: Dual-specificity tyrosineregulated kinase 2; ER: Estrogen Receptor; Al: Aromatase inhibitors; MIEN1: Migration and invasion enhancer; PTEN: Phosphatase and tensin homolog; ILC: Invasive lobular breast carcinoma; SIRP-a: Signal-regulatory protein alpha; CD47-SIRPa: Cluster differentiation 47- signal-regulatory protein alpha; TCR: T-cell receptor; CAR T cell: Chimeric antigen receptor T cell; KRAB: Krüppel-associated box; H3K9me3: Histone3 lysin 9 triple methylation SRC-1 : Steroid receptor coactivator 1; qPCR: Quantitative PCR; TP53: Tumor protein 53; PPABLG: a-helical polypeptide; P-HNPs: A PEGylated nanoparticles based on the cationic a-helical polypeptide poly(y-4-((2-(piperidin-1-yl)ethyl)aminomethyl)benzyl-I-glutamate; DSB: Double strand break; Fokl: Endonuclease isolated from Flavobacteria okeanokoites I; MYBPC3: Myosin Binding Protein C, Cardiac; E7: Early viral protein
\end{abstract}

\section{Acknowledgements}

Not Applicable.

\section{Authors' contributions}

HS: conceptualized the idea and wrote the manuscript, SA, HT, and AA revised the manuscript, EC drew the figures and illustrations, FA and AfA collected the data. The author(s) read and approved the final manuscript.

\section{Funding}

This work has not received any funds from any funding bodies.

Availability of data and materials

All data analyzed and reviewed are included in this article.

\section{Declarations}

Ethics approval and consent to participate

Not Applicable.

\section{Consent for publication}

All authors confirm their participation and approve the submission.

\section{Competing interests}

The authors declare no conflict of interests.

\section{Author details}

${ }^{1}$ Department of Genetics, Institute for Medical Research and Consultations, Imam Abdulrahman Bin Faisal University, P. O. Box: 1982, Dammam 31441, Saudi Arabia. ${ }^{2}$ Department of Environmental Biotechnology, College of Biotechnology, Misr University for Science and Technology, P. O. Box 77, Giza, Egypt. ${ }^{3}$ Department of Biology, College of Science, Imam Abdulrahman Bin Faisal University, P. O. 4 Box, Dammam 1982, Saudi Arabia. ${ }^{4}$ Breast Imaging Division, KFHU, Imam Abdulrahman Bin Faisal University, P. O. 4 Box, Dammam 1982, Saudi Arabia.

Received: 13 January 2021 Accepted: 12 April 2021

Published online: 29 April 2021

References

1. Ratan ZA, Son YJ, Haidere MF, Uddin BMM, Yusuf MA, Bin Zaman S, et al. CRISPR-Cas9: a promising genetic engineering approach in cancer research. Therapeutic Advances Med Oncol. 2018;10:1758834018755089.

2. Katrekar D, Hu M, Mali P. Advances in CRISPR-Cas based genome engineering. Curr Opinion Biomed Eng. 2017;1:78-86. https://doi.org/10.101 6/j.cobme.2017.04.001.

3. Chew WL. Immunity to CRISPR Cas9 and Cas12a therapeutics. Wiley Interdisciplinary Reviews: Syst Biol Med. 2018;10(1):n/a.

4. Wang HX, Song Z, Lao YH, Xu X, Gong J, Cheng D, et al. Nonviral gene editing via CRISPR/Cas9 delivery by membrane-disruptive and endosomolytic helical polypeptide. Proc Natl Acad Sci U S A. 2018;115(19): 4903-8. https://doi.org/10.1073/pnas.1712963115.

5. Gao Y, Widschwendter M, Teschendorff AE. DNA methylation patterns in Normal tissue correlate more strongly with breast Cancer status than copynumber variants. EBioMedicine. 2018;31:243-52. https://doi.org/10.1016/j. ebiom.2018.04.025.

6. DeSantis CE, Ma J, Goding Sauer A, Newman LA, Jemal A. Breast cancer statistics, 2017, racial disparity in mortality by state: breast Cancer statistics, 2017. CA Cancer J Clin. 2017;67(6):439-48. https://doi.org/10.3322/caa C.21412.

7. Vogel VG. 15 - Epidemiology of Breast Cancer. In: Bland KI, Copeland EM, Klimberg VS, Gradishar WJ, editors. The Breast (Fifth Edition): Elsevier; 2018. p. 207-18. e4.

8. Jones T, Lockhart JS, Mendelsohn-Victor KE, Duquette D, Northouse LL, Duffy SA, et al. Use of Cancer genetics Services in African-American Young Breast Cancer Survivors. Am J Prev Med. 2016;51(4):427-36. https://doi.org/1 0.1016/j.amepre.2016.03.016.

9. Banerjee B, Sherwood RI. A CRISPR view of gene regulation. Curr Opin Syst Biol. 2017;1:1-8. https://doi.org/10.1016/j.coisb.2016.12.016.

10. Zuckermann M, Kawauchi D, Gronych J. Applications of the CRISPR/Cas9 system in murine cancer modeling. Brief Funct Genomics. 2017;16(1):25-33. https://doi.org/10.1093/bfgp/elw021.

11. Ishino Y, Krupovic M, Forterre P. History of CRISPR-Cas from encounter with a mysterious repeated sequence to genome editing technology. J Bacteriol. 2018;200(7)

12. Mojica FJ, Juez G, Rodríguez-Valera F. Transcription at different salinities of Haloferax mediterranei sequences adjacent to partially modified Pstl sites. Mol Microbiol. 1993;9(3):613-21. https://doi.org/10.1111/j.1365-2958.1993. tb01721.x

13. Kim YG, Cha J, Chandrasegaran S. Hybrid restriction enzymes: zinc finger fusions to Fok I cleavage domain. Proc Natl Acad Sci U S A. 1996;93(3): 1156-60. https://doi.org/10.1073/pnas.93.3.1156.

14. Smith J, Bibikova M, Whitby FG, Reddy AR, Chandrasegaran S, Carroll D. Requirements for double-strand cleavage by chimeric restriction enzymes with zinc finger DNA-recognition domains. Nucleic Acids Res. 2000;28(17): 3361-9. https://doi.org/10.1093/nar/28.17.3361. 
15. Bibikova M, Golic M, Golic KG, Carroll D. Targeted chromosomal cleavage and mutagenesis in Drosophila using zinc-finger nucleases. Genetics. 2002; 161(3):1169-75.

16. Jansen R. Embden JDAv, Gaastra W, Schouls LM. Identification of genes that are associated with DNA repeats in prokaryotes. Mol Microbiol. 2002;43(6): 1565-75. https://doi.org/10.1046/j.1365-2958.2002.02839.x.

17. Lloyd A, Plaisier CL, Carroll D, Drews GN. Targeted mutagenesis using zincfinger nucleases in Arabidopsis. Proc Natl Acad Sci U S A. 2005;102(6):22327. https://doi.org/10.1073/pnas.0409339102.

18. Bolotin A, Quinquis B, Sorokin A, Ehrlich SD. Clustered regularly interspaced short palindrome repeats (CRISPRs) have spacers of extrachromosomal origin. Microbiology. 2005;151(8):2551-61. https://doi.org/10.1099/mic.0.2804 8-0.

19. Makarova KS, Grishin NV, Shabalina SA, Wolf YI, Koonin EV. A putative RNAinterference-based immune system in prokaryotes: computational analysis of the predicted enzymatic machinery, functional analogies with eukaryotic RNAi, and hypothetical mechanisms of action. Biology direct. 2006;1(1):7.

20. Stan JJB, Jore MM, Lundgren M, Westra ER, Rik JHS, Ambrosius PLS, et al. Small CRISPR RNAs quide antiviral defense in prokaryotes. Science. 2008; 321(5891):960-4.

21. Dupuis M-Ė, Villion M, Fremaux C, Horvath P, Magadán AH, Romero DA, et al. The CRISPR/Cas bacterial immune system cleaves bacteriophage and plasmid DNA. Nature. 2010;468(7320):67-71.

22. Deltcheva E, Chylinski K, Sharma CM, Gonzales K, Chao Y, Pirzada ZA, et al. CRISPR RNA maturation by trans-encoded small RNA and host factor RNase III. Nature. 2011;471(7340):602-7. https://doi.org/10.1038/nature09886.

23. Gasiunas G, Barrangou R, Horvath P, Siksnys V. Cas9-crRNA ribonucleoprotein complex mediates specific DNA cleavage for adaptive immunity in bacteria. Proc Natl Acad Sci. 2012;109(39):E2579-86. https://doi. org/10.1073/pnas.1208507109.

24. Jinek M, Chylinski K, Fonfara I, Hauer M, Doudna JA, Charpentier E, et al. A programmable dual-RNA — guided DNA endonuclease in adaptive bacterial immunity. Science. 2012;337(6096):816-21. https://doi.org/10.1126/ science.1225829.

25. Shalem O, Sanjana NE, Zhang F. High-throughput functional genomics using CRISPR-Cas9. Nat Rev Genet. 2015;16(5):299-311. https://doi.org/10.1 038/nrg3899.

26. Zetsche B, Gootenberg Jonathan S, Abudayyeh Omar O, Slaymaker lan M, Makarova Kira S, Essletzbichler P, et al. Cpf1 is a single RNA-guided endonuclease of a class 2 CRISPR-Cas system. Cell. 2015;163(3):759-71. https://doi.org/10.1016/j.cell.2015.09.038.

27. Liang $P, X u Y$, Zhang X, Ding C, Huang R, Zhang Z, et al. CRISPR/Cas9mediated gene editing in human tripronuclear zygotes. 蛋白质与细胞:英 文版. 2015;6(5):363-72

28. Regan PM, Langford D, Khalili K. Regulation and functional implications of Opioid receptor splicing in Opioid pharmacology and HIV Pathogenesis: OPIOID RECEPTOR SPLICING IN HIV PATHOGENESIS. J Cell Physiol. 2016; 231(5):976-85. https://doi.org/10.1002/jcp.25237.

29. Esvelt K. Gene editing can drive science to openness. Nature. 2016; 534(7606):153.

30. Lee K, Conboy M, Park HM, Jiang F, Kim HJ, Dewitt MA, et al. Nanoparticle delivery of Cas9 ribonucleoprotein and donor DNA in vivo induces homology-directed DNA repair. Nat Biomed Eng. 2017;1(11):889-901. https://doi.org/10.1038/s41551-017-0137-2.

31. Morales DP, Morgan EN, MCAdams M, Chron AB, Shin JE, Zasadzinski JA, et al. Light-Triggered Genome Editing: Cre Recombinase Mediated Gene Editing with Near-Infrared Light. Small. 2018;14(30):e1800543-n/a.

32. Zhang X, Xu L, Fan R, Gao Q, Song Y, Lyu X, et al. Genetic editing and interrogation with Cpf1 and caged truncated pre-tRNA-like crRNA in mammalian cells. Cell Discov. 2018;4(1).

33. Chow RD, Kim HR, Chen S. Programmable sequential mutagenesis by inducible Cpf1 crRNA array inversion. Nat Commun. 2018;9(1).

34. Zhao C, Zhao Y, Zhang J, Lu J, Chen L, Zhang Y, et al. HIT-Cas9: a CRISPR/ Cas9 genome editing device under tight and effective drug control. Mol Therap-Nucleic Acids. 2018;13:208-19. https://doi.org/10.1016/j.omtn.2018. 08.022 .

35. Ahmad G, Amiji M. Use of CRISPR/Cas9 gene-editing tools for developing models in drug discovery. Drug Discov Today. 2018;23(3):519-33. https://doi. org/10.1016/j.drudis.2018.01.014.

36. Du Toit A. What CRISPR memories are made of: Bacterial genetics. Nat Rev Microbiol. 2015;13(4):185
37. Raj VS. 29 - Cancer Rehabilitation. In: Cifu DX, Lew HL, editors. Braddom's Rehabilitation Care: A Clinical Handbook: Elsevier; 2018. p. 197-203. e12.

38. Autier P. Age at cancer diagnosis and interpretation of survival statistics. Lancet Oncol. 2016;17(7):847-8. https://doi.org/10.1016/S1470-2045(16)30048-1.

39. Yang HT, Jaeger M, Walker A, Wei D, Leiker K, Tao WT. Break breast Cancer addiction by CRISPR/Cas9 genome editing. J Cancer. 2018;9(2):219-31. https://doi.org/10.7150/jca.22554.

40. Kannan $\mathrm{R}$, Ventura $\mathrm{A}$. The CRISPR revolution and its impact on cancer research. Swiss Med Wkly. 2015;145:w14230.

41. Sanchez-Rivera FJ, Jacks T. Applications of the CRISPR-Cas9 system in cancer biology. Nat Rev Cancer. 2015;15(7):387-95. https://doi.org/10.1038/nrc3950.

42. Maddalo D, Manchado E, Concepcion CP, Bonetti C, Vidigal JA, Han Y-C, et al. In vivo engineering of oncogenic chromosomal rearrangements with the CRISPR/ Cas9 system. Nature. 2014;516(7531):423-8. https://doi.org/10.1038/nature13902.

43. Malina A, Mills JR, Cencic R, Yan Y, Fraser J, Schippers LM, et al. Repurposing CRISPR/Cas9 for in situ functional assays. Genes Dev. 2013;27(23):2602-14. https://doi.org/10.1101/gad.227132.113.

44. Baliou S, Adamaki M, Kyriakopoulos AM, Spandidos DA, Panayiotidis M, Christodoulou I, et al. CRISPR therapeutic tools for complex genetic disorders and cancer (review). Int J Oncol. 2018;53(2):443-68. https://doi. org/10.3892/ijo.2018.4434

45. Chiou S-H, Winters IP, Wang J, Naranjo S, Dudgeon C, Tamburini FB, et al. Pancreatic cancer modeling using retrograde viral vector delivery and in vivo CRISPR/Cas9-mediated somatic genome editing. Genes Dev. 2015; 29(14):1576-85. https://doi.org/10.1101/gad.264861.115.

46. Chen F, Wang Y, Yuan Y, Zhang W, Ren Z, Jin Y, et al. Generation of B celldeficient pigs by highly efficient CRISPR/Cas9-mediated gene targeting. J Genet Genom = Yi chuan xue bao. 2015:42(8):437-44.

47. Antal C, Hudson A, Kang E, Zanca C, Wirth C, Stephenson N, et al. Cancerassociated protein kinase $C$ mutations reveal Kinase's role as tumor suppressor. Cell. 2014;160(3):489-502.

48. Matano M, Date S, Shimokawa M, Takano A, Fujii M, Ohta Y, et al. Modeling colorectal cancer using CRISPR-Cas9-mediated engineering of human intestinal organoids. Nat Med. 2015;21(3):256-62. https://doi.org/10.1038/ nm.3802.

49. Drost J, van Boxtel R, Blokzijl F, Mizutani T, Sasaki N, Sasselli V, et al. Use of CRISPR-modified human stem cell organoids to study the origin of mutational signatures in cancer. Science. 2017;358(6360):234.

50. Lee W, Lee JH, Jun S, Bang D. Selective targeting of KRAS oncogenic alleles by CRISPR/Cas9 inhibits proliferation of cancer cells. Sci Rep. 2018;8(1): 11879-7. https://doi.org/10.1038/s41598-018-30205-2

51. Kim W, Lee S, Kim HS, Song M, Cha YH, Kim Y-H, et al. Targeting mutant KRAS with CRISPR-Cas9 controls tumor growth. Genome Res. 2018;28(3): 374-82. https://doi.org/10.1101/gr.223891.117.

52. Chen L, Peng M, Li N, Song Q, Yao Y, Xu B, et al. Combined use of EpCAM and FRa enables the high-efficiency capture of circulating tumor cells in non-small cell lung cancer. Scientific Rep. 2018;8(1).

53. Chen S, Sanjana Neville E, Zheng K, Shalem O, Lee K, Lee H, et al. Genomewide CRISPR screen in a mouse model of tumor growth and metastasis. Cell. 2015;160(6):1246-60. https://doi.org/10.1016/j.cell.2015.02.038.

54. Takaku M, Grimm SA, Roberts JD, Chrysovergis K, Bennett BD, Myers P, et al GATA3 zinc finger 2 mutations reprogram the breast cancer transcriptional network. Nat Commun. 2018:9(1).

55. Linde N, Casanova-Acebes M, Sosa MS, Mortha A, Rahman A, Farias E, et al. Macrophages orchestrate breast cancer early dissemination and metastasis. Nat Commun. 2018;9(1)

56. Zhang Z, Christin JR, Wang C, Ge K, Oktay MH, Guo W. Mammary-stem-cellbased somatic mouse models reveal breast Cancer drivers causing cell fate Dysregulation. Cell Rep. 2016;16(12):3146-56. https://doi.org/10.1016/j. celrep.2016.08.048

57. Wang Y, Wang Zhigang C, Zhang T, Kwiatkowski N, Abraham Brian J, Lee Tong I, et al. CDK7-dependent transcriptional addiction in triple-negative breast Cancer. Cell. 2015;163(1):174-86. https://doi.org/10.1016/j.cell.2015.08.063.

58. Ain QU, Chung JY, Kim Y-H. Current and future delivery systems for engineered nucleases: ZFN, TALEN and RGEN. J Control Release. 2015;205: 120-7. https://doi.org/10.1016/j.jconrel.2014.12.036.

59. Gupta RM, Musunuru K. Expanding the genetic editing tool kit: ZFNs, TALE Ns, and CRISPR-Cas9. J Clin Invest. 2014;124(10):4154-61. https://doi.org/1 $0.1172 / J C l 72992$

60. Xu X, Qi LS. A CRISPR-dCas toolbox for genetic engineering and synthetic biology. J Mol Biol. 2019;431(1):34-47. 
61. Catuogno S, Esposito CL, Ungaro P, de Franciscis V. Nucleic Acid Aptamers Targeting Epigenetic Regulators: An Innovative Therapeutic Option. Pharmaceuticals (Basel, Switzerland). 2018;11(3):79.

62. Spitale RC, Tsai M-C, Chang HY. RNA templating the epigenome: long noncoding RNAs as molecular scaffolds. Epigenetics. 2011;6(5):539-43. https://doi.org/10.4161/epi.6.5.15221.

63. Farhang N, Brunger JM, Stover JD, Thakore PI, Lawrence B, Guilak F, et al. CRISPR-based Epigenome editing of cytokine receptors for the promotion of cell survival and tissue deposition in inflammatory environments. Tissue Eng A. 2017;23(15-16):738-49. https://doi.org/10.1089/ten.tea.2016.0441.

64. Qin W, Xiong Y, Chen J, Huang Y, Liu T. DC-CIK cells derived from ovarian cancer patient menstrual blood activate the TNFR1-ASK1-AIP1 pathway to kill autologous ovarian cancer stem cells. J Cell Mol Med. 2018;22(7):336476. https://doi.org/10.1111/jcmm.13611.

65. Xu H, Sun Q, Lu J, Lu L, Luo F, Zhou L, et al. MicroRNA-218 acts by repressing TNFR1-mediated activation of NF-KB, which is involved in MUC5AC hyper-production and inflammation in smoking-induced bronchiolitis of COPD. Toxicol Lett. 2017;280:171-80. https://doi.org/10.1016/ j.toxlet.2017.08.079.

66. Kennedy EM, Kornepati AVR, Goldstein M, Bogerd HP, Poling BC, Whisnant AW, et al. Inactivation of the human papillomavirus E6 or E7 gene in cervical carcinoma cells by using a bacterial CRISPR/Cas RNA-guided endonuclease. J Virol. 2014;88(20):11965-72. https://doi.org/10.1128/JVI.01 879-14.

67. Moses C, Garcia-Bloj B, Harvey AR, Blancafort P. Hallmarks of cancer: the CRISPR generation. Eur J Cancer. 2018;93:10-8. https://doi.org/10.1016/j. ejca.2018.01.002

68. Wang C, Zou J, Ma X, Wang E, Peng G. Mechanisms and implications of ADAR-mediated RNA editing in cancer. Cancer Lett. 2017:411:27-34. https:// doi.org/10.1016/j.canlet.2017.09.036.

69. Jubin T, Kadam A, Jariwala M, Bhatt S, Sutariya S, Gani AR, et al. The PARP family: insights into functional aspects of poly (ADP-ribose) polymerase-1 in cell growth and survival. Cell Prolif. 2016;49(4):421-37. https://doi.org/1 $0.1111 /$ cpr.12268.

70. Advani SM, Advani P, DeSantis SM, Brown D, VonVille HM, Lam M, et al. Clinical, pathological, and molecular characteristics of CpG Island Methylator phenotype in colorectal Cancer: a systematic review and meta-analysis. Transl Oncol. 2018;11(5):1188-201. https://doi.org/10.1016/j.tranon.2018.07.008.

71. Banerjee S, Ji C, Mayfield JE, Goel A, Xiao J, Dixon JE, et al. Ancient drug curcumin impedes 265 proteasome activity by direct inhibition of dualspecificity tyrosine-regulated kinase 2. Proc Natl Acad Sci U S A. 2018; 115(32):8155-60. https://doi.org/10.1073/pnas.1806797115.

72. Chen L, Zhu G, Johns EM, Yang X, et al. Nat Commun. 2018;9(1).

73. Guo X, Wang X, Wang Z, Banerjee S, Yang J, Huang L, et al. Site-specific proteasome phosphorylation controls cell proliferation and tumorigenesis. Nat Cell Biol. 2016;18(2):202-12. https://doi.org/10.1038/ncb3289.

74. Pavlin M, Spinello A, Pennati M, Zaffaroni N, Gobbi S, Bisi A, et al. A Computational Assay of Estrogen Receptor a Antagonists Reveals the Key Common Structural Traits of Drugs Effectively Fighting Refractory Breast Cancers. Scientific Rep. 2018;8(1).

75. Fang Z, Yi Y, Shi G, Li S, Chen S, Lin Y, et al. Role of Brf1 interaction with $\mathrm{ERa}$, and significance of its overexpression, in human breast cancer. Mol Oncol. 2017;11(12):1752-67. https://doi.org/10.1002/1878-0261.12141.

76. Van Treuren T, Vishwanatha JK. CRISPR deletion of MIEN1 in breast cancer cells. PLoS One. 2018;13(10):e0204976. https://doi.org/10.1371/journal.pone. 0204976.

77. Annunziato S, Kas SM, Nethe M, Yücel H, Del Bravo J, Pritchard C, et al Modeling invasive lobular breast carcinoma by CRISPR/Cas9-mediated somatic genome editing of the mammary gland. Genes Dev. 2016;30(12): 1470-80. https://doi.org/10.1101/gad.279190.116.

78. Russ A, Hua AB, Montfort WR, Rahman B, Riaz IB, Khalid MU, et al. Blocking "don't eat me" signal of CD47-SIRPa in hematological malignancies, an indepth review. Blood Rev. 2018;32(6):480-9. https://doi.org/10.1016/j.blre.201 8.04.005.

79. Fan P, He ZY, Xu T, Phan K, Chen GG, Wei YQ. Exposing cancer with CRISPRCas9: from genetic identification to clinical therapy. Transl Cancer Res. 2018; 7(3):817-27. https://doi.org/10.21037/tcr.2018.06.16.

80. Thakore PI, D'Ippolito AM, Song L, Safi A, Shivakumar NK, Kabadi AM, et al. Highly specific epigenome editing by CRISPR-Cas9 repressors for silencing of distal regulatory elements. Nat Methods. 2015;12(12):1143-9. https://doi. org/10.1038/nmeth.3630.
81. O'Donnell KA. Advances in functional genetic screening with transposons and CRISPR/Cas9 to illuminate cancer biology. Curr Opin Genet Dev. 2018; 49:85-94. https://doi.org/10.1016/j.gde.2018.03.006.

82. Ward E, Varešlija D, Charmsaz S, Fagan A, Browne AL, Cosgrove N, et al. Epigenome-wide SRC-1-mediated gene silencing represses cellular differentiation in advanced breast Cancer. Clin Cancer Res. 2018:24(15): 3692-703. https://doi.org/10.1158/1078-0432.CCR-17-2615.

83. Kalhor R, Mali P, Church GM, et al. Nat Methods. 2017;14(2):195 U6 - ctx_ ver=Z3988-2004\&ctx_enc=info\%3Aofi\%2Fenc\%3AUTF-8\&rfr_id= info\%3Asid\%2Fsummonserialssolutionscom\&rft_val_fmt= info\%3Aofi\%2Ffmt\%3Akev\%3Amtx\%3Ajournal\&rftgenre=article\&rftatitle= Rapidly+evolving+homing+CRISPR+barcodes\&rftjtitle=Nature+ methods\&rftau=Kalhor\%2C+Reza\&rftau=Mali\%2C+Prashant\&rftau= Church\%2C+George+M\&rftdate $=2017-02-01 \&$ rfteissn $=1548-$ 7105\&rftvolume $=14 \&$ rftissue $=2 \&$ rftspage $=195 \&$ rft_id $=$ info\%3Apmid\%2F27918539\&rftexternalDocID=27918539\&paramdict=en-US U7 - Journal Article.

84. Kozak D, Głowacka-Mrotek I, Nowikiewicz T, Siedlecki Z, Hagner W, Sowa M, et al. Analysis of undesirable Sequelae of sentinel node surgery in breast Cancer patients - a prospective cohort study. Pathol Oncol Res. 2018;24(4): 891-7. https://doi.org/10.1007/s12253-017-0306-3.

85. Dirix LY, Takacs I, Jerusalem G, Nikolinakos P, Arkenau HT, Forero-Torres A, et al. Avelumab, an anti-PD-L1 antibody, in patients with locally advanced or metastatic breast cancer: a phase 1b JAVELIN solid tumor study. Breast Cancer Res Treat. 2018;167(3):671-86. https://doi.org/10.1007/s10549-017-4537-5.

86. Chen Y, Zhang Y. Application of the CRISPR/Cas9 System to Drug Resistance in Breast Cancer. Advanc Sci. 2018;5(6).

87. Hill AJ, McFaline-Figueroa JL, Starita LM, Gasperini MJ, Matreyek KA, Packer J, et al. On the design of CRISPR-based single-cell molecular screens. Nat Methods. 2018;15(4):271-4. https://doi.org/10.1038/nmeth.4604.

88. Hegde M, Strand C, Hanna RE, Doench JG. Uncoupling of sgRNAs from their associated barcodes during PCR amplification of combinatorial CRISPR screens. PloS one. 2018;13(5).

89. McKenna A, Findlay GM, Gagnon JA, Horwitz MS, Schier AF, Shendure J. Whole-organism lineage tracing by combinatorial and cumulative genome editing. Science (New York, NY). 2016;353(6298):aaf7907.

90. Moiseenko F, Volkov N, Bogdanov A, Dubina M, Moiseyenko V. Resistance mechanisms to drug therapy in breast cancer and other solid tumors: An opinion. F1000Res. 2017;6:288.

91. Oppel F, Schürmann M, Goon P, Albers AE, Sudhoff H. Specific targeting of oncogenes using CRISPR technology. Cancer Res. 2018;78(19):5506-12. https://doi.org/10.1158/0008-5472.CAN-18-0571.

92. Schmelas C, Grimm D. Split Cas9, Not Hairs - Advancing the Therapeutic Index of CRISPR Technology. Biotechnol J. 2018;13(9).

93. Kühn R, Chu VT. Pop in, pop out: a novel gene-targeting strategy for use with CRISPR-Cas9. Genome Biol. 2015;16(1):244. https://doi.org/10.1186/s13 059-015-0810-2.

94. Mollanoori H, Shahraki H, Rahmati Y, Teimourian S. CRISPR/Cas9 and CAR-T cell, collaboration of two revolutionary technologies in cancer immunotherapy, an instruction for successful cancer treatment. Hum Immunol. 2018;79(12):876-82. https://doi.org/10.1016/j.humimm.2018.09.007.

95. Hochheiser K, Kueh AJ, Gebhardt T, Herold MJ. CRISPR/Cas9: a tool for immunological research. Eur J Immunol. 2018;48(4):576-83. https://doi.org/1 0.1002/eji.201747131.

96. Montano A, Forero-Castro M, Hernandez-Rivas JM, Garcia-Tunon I, Benito R. Targeted genome editing in acute lymphoblastic leukemia: a review. BMC Biotechnol. 2018;18(1):45-10. https://doi.org/10.1186/s12896-018-0455-9.

97. Modell JW, Jiang W, Marraffini LA. CRISPR-Cas systems exploit viral DNA injection to establish and maintain adaptive immunity. Nature. 2017; 544(7648):101-4. https://doi.org/10.1038/nature21719.

98. Liang C, Li F, Li J, Wang C, Wang L, Zhang G, et al. Tumor cell-targeted delivery of CRISPR/Cas9 by aptamer-functionalized lipopolymer for therapeutic genome editing of VEGFA in osteosarcoma. Biomaterials. 2017; 147:68-85. https://doi.org/10.1016/j.biomaterials.2017.09.015.

99. Jubair L, McMillan NAJ. The therapeutic potential of CRISPR/Cas9 Systems in Oncogene-Addicted Cancer Types: virally driven cancers as a model system. Mol Therap - Nucleic Acids. 2017;8:56-63. https://doi.org/10.1016/j.omtn.201 7.06.006.

100. Gong S, Yu HH, Johnson KA, Taylor DW. DNA unwinding is the primary determinant of CRISPR-Cas9 activity. Cell Rep. 2018;22(2):359-71. https://doi. org/10.1016/j.celrep.2017.12.041. 
101. Xiao A, Cheng Z, Kong L, Zhu Z, Lin S, Gao G, et al. CasOT: a genome-wide Cas9/gRNA off-target searching tool. Bioinformatics. 2014;30(8):1180-2. https://doi.org/10.1093/bioinformatics/btt764.

102. Iyer V, Boroviak K, Thomas M, Doe B, Riva L, Ryder E, et al. No unexpected CRISPR-Cas9 off-target activity revealed by trio sequencing of gene-edited mice. PLoS Genet. 2018;14(7).

103. Kimberland ML, Hou W, Alfonso-Pecchio A, Wilson S, Rao Y, Zhang S, et al. Strategies for controlling CRISPR/Cas9 off-target effects and biological variations in mammalian genome editing experiments. J Biotechnol. 2018; 284:91-101. https://doi.org/10.1016/j.jbiotec.2018.08.007.

104. Liu C, Zhang L, Liu H, Cheng K. Delivery strategies of the CRISPR-Cas9 geneediting system for therapeutic applications. J Control Release. 2017;266:1726. https://doi.org/10.1016/.j.jonrel.2017.09.012.

105. Kleinstiver BP, Pattanayak V, Prew MS, Tsai SQ, Nguyen NT, Zheng Z, et al. Highfidelity CRISPR-Cas9 nucleases with no detectable genome-wide off-target effects. Nature. 2016;529(7587):490-5. https://doi.org/10.1038/nature16526.

106. Chira S, Gulei D, Hajitou A, Zimta A-A, Cordelier P, Berindan-Neagoe I. CRIS PR/Cas9: transcending the reality of genome editing. Mol Therap - Nucleic Acids. 2017;7:211-22. https://doi.org/10.1016/j.omtn.2017.04.001.

107. Klose RJ, Cooper S, Farcas AM, Blackledge NP, Brockdorff N. Chromatin sampling-an emerging perspective on targeting Polycomb repressor proteins. PLoS Genet. 2013;9(8):e1003717. https://doi.org/10.1371/journal. pgen.1003717

108. Hay EA, Khalaf AR, Marini P, Brown A, Heath K, Sheppard D, et al. An analysis of possible off target effects following CAS9/CRISPR targeted deletions of neuropeptide gene enhancers from the mouse genome. Neuropeptides. 2017;64:101-7. https://doi.org/10.1016/j.npep.2016.11.003.

109. Havlicek S, Shen Y, Alpagu Y, Bruntraeger MB, Zufir NB, Phuah ZY, et al. Reengineered RNA-guided Fokl-nucleases for improved genome editing in human cells. Mol Therap. 2017;25(2):342-55. https://doi.org/10.1016/j. ymthe.2016.11.007.

110. Zhang X-H, Tee LY, Wang X-G, Huang Q-S, Yang S-H. Off-target effects in CRISPR/Cas9-mediated genome engineering. Mol Therap - Nucleic Acids. 2015;4(11):e264. https://doi.org/10.1038/mtna.2015.37.

111. Hannafon BN, Cai A, Calloway CL, Xu YF, Zhang R, Fung KM, et al. miR-23b and miR-27b are oncogenic microRNAs in breast cancer: evidence from a CRISPR/Cas9 deletion study. BMC cancer. 2019;19(1):642.

112. Annunziato S, Lutz C, Henneman L, Bhin J, Wong K, Siteur B, et al. In situ CRISPR-Cas9 base editing for the development of genetically engineered mouse models of breast cancer. EMBO J. 2020;39(5):e102169. https://doi. org/10.15252/embj.2019102169.

113. Campbell KJ, Blyth K. Somatic base editing to model oncogenic drivers in breast cancer. Lab Anim (NY). 2020;49(4):115-6. https://doi.org/10.1038/s41 684-020-0510-8.

114. Albitar A, Rohani B, Will B, Yan A, Gallicano GI. The application of CRISPR/Cas technology to efficiently model complex Cancer genomes in stem cells. J Cell Biochem. 2018;119(1):134-40. https://doi.org/10.1002/jcb.26195.

115. Bailey J. CRISPR-mediated gene editing: scientific and ethical issues. Trends Biotechnol. 2019;37(9):920-1. https://doi.org/10.1016/j.tibtech.2019.05.002.

116. Bartkowski B, Theesfeld I, Pirscher F, Timaeus J. Snipping around for food: economic, ethical and policy implications of CRISPR/Cas genome editing. Geoforum. 2018;96:172-80. https://doi.org/10.1016/j.geoforum.2018.07.017.

117. Haapaniemi E, Botla S, Persson J, Schmierer B, Taipale J. CRISPR-Cas9 genome editing induces a p53-mediated DNA damage response. Nat Med. 2018;24(7):927-30. https://doi.org/10.1038/s41591-018-0049-z.

\section{Publisher's Note}

Springer Nature remains neutral with regard to jurisdictional claims in published maps and institutional affiliations.

Ready to submit your research? Choose BMC and benefit from:

- fast, convenient online submission

- thorough peer review by experienced researchers in your field

- rapid publication on acceptance

- support for research data, including large and complex data types

- gold Open Access which fosters wider collaboration and increased citations

- maximum visibility for your research: over $100 \mathrm{M}$ website views per year

At BMC, research is always in progress.

Learn more biomedcentral.com/submissions 